\title{
The role of oxidative stress in ovarian toxicity induced by haloperidol and clozapine-a histological and biochemical study in albino rats
}

\author{
Hanaa Attia Khalaf ${ }^{1}$ • Ekramy Elmorsy ${ }^{2} \cdot$ El-Hassanin Mohamed Mahmoud ${ }^{3} \cdot$ Amal Misbah Aggour $^{4} \cdot$ Saad A. Amer $^{5}$ (D)
}

Received: 26 October 2018 / Accepted: 1 July 2019 / Published online: 24 July 2019

(C) The Author(s) 2019

\begin{abstract}
Oxidative stress has been implicated in reproductive toxicity induced by antipsychotics (APs). This study aims to further investigate the role of AP-induced oxidative stress in reproductive dysfunction. Thirty adult female albino rats were divided into three groups including a control group $(n=10)$ receiving distilled water, HAL group $(n=10)$ receiving haloperidol (HAL) $(2 \mathrm{mg} / \mathrm{kg} / \mathrm{day})$, and CLZ group $(n=10)$ receiving clozapine (CLZ) $(20 \mathrm{mg} / \mathrm{kg} /$ day). After 28 days, the rats were anesthetized, blood was withdrawn from their hearts, and ovaries were removed before they were sacrificed. Serum prolactin concentrations were measured. For each rat, one ovary was used for biochemical studies including mitochondrial complexes I and III activities and oxidative stress markers (lipid peroxidation, super oxide dismutase [SOD], catalase [CAT], and reduced glutathione [GSH]). The other ovary was used for histopathological examination and immunohistochemistry staining for p53 and Ki-67. HAL-treated rats showed significantly $(p<0.001)$ higher serum prolactin concentrations compared with other groups. HAL significantly inhibited complexes I $(p<0.001)$ and III activities $(p<0.05)$, while CLZ inhibited only complex I $(p<0.001)$. Lipid peroxidation was increased by HAL $(p<0.001)$ and CLZ $(p<0.01)$. HAL caused significant $(p<0.001)$ reductions in SOD, CAT, and GSH. CLZ caused a significant decrease in SOD $(p<0.001)$ and GSH $(p<0.01)$ with no effect on CAT. Histopathological studies of CLZ- and HAL-treated ovaries showed features suggestive of hyperprolactinemia and oxidative stress. Ki-67- and P53-immunostained sections were suggestive of disruption of cellular proliferation. These findings support the hypothesis that HAL and CLZ induce reproductive dysfunction through mechanisms involving ovarian mitochondrial dysfunction and oxidative stress.
\end{abstract}

Keywords Antipsychotics $\cdot$ Oxidative stress $\cdot$ Reproductive toxicity $\cdot$ Ovarian toxicity $\cdot$ Menstrual irregularities

\section{Introduction}

Since the 1950s, antipsychotics (APs) have been widely used in patients with psychosis and bipolar disorders (Lin et al.

Saad A. Amer

saad.amer@nottingham.ac.uk

1 Department of Histology \& Cell Biology, Faculty of Medicine, Mansoura University, Mansoura, Egypt

2 Department of Forensic Medicine and Clinical Toxicology, Faculty of Medicine, Mansoura University, Mansoura, Egypt

3 Department of Psychiatry, Mansoura Faculty Medicine, Mansoura, Egypt

4 Arar Maternity and Children Hospital, Ministry of Health, Riyadh, Kingdom of Saudi Arabia

5 Division of Medical Sciences \& Graduate Entry Medicine, Royal Derby Hospital, School of Medicine, University of Nottingham, Uttoxeter Road, Derby DE22 3DT, UK
2006). Typical APs produce numerous adverse effects as extrapyramidal movements, weight gain, diabetes, and reproductive dysfunctions in women. These untoward side effects limit the tolerability of APs, which is a challenging problem in long-term users (Bishnoi et al. 2007). It has long been believed that typical APs induce ovarian dysfunction indirectly by means of hyperprolactinemia as a result of their stimulatory effects on the dopaminergic receptors (D2 receptor) of the tubule-infundibular pathway. This is supported by the observation that serum prolactin levels increase within a few hours of initiation of AP treatment (Halbreich et al. 2003; Kumar et al. 2013). This hyperprolactinemia has been reported to occur with greater magnitude in women compared with men (Smith et al. 2002). High serum prolactin levels are known to cause ovulatory dysfunction by inhibiting follicle-stimulating hormone (FSH) (Majumdar and Manga 2013) as well as follicular estradiol secretion (Velasquez et al. 2006).

More recently, novel less toxic and prolactin-sparing APs have been developed such as clozapine (CLZ), olanzapine 
(OLZ), quetiapine (QTN), risperidone (RIS), amisulpride, zotepine, and ziprasidone (Daniel and Copeland 2000; Rung et al. 2011). However, these prolactin-sparing APs have been found to induce reproductive dysfunction in women to the same extent as the earlier APs, which induce hyperprolactinemia (Canuso et al. 2002). These findings, therefore, suggest that AP-induced hyperprolactinemia, alone, may not adequately explain the observed AP-induced ovarian dysfunction; hence the need to investigate for other possible mechanisms.

Several previous studies have reported in vitro and in vivo evidence for the association between cytotoxicity and APinduced oxidative stress in non-reproductive tissues (Martins et al. 2008, El-Awdan et al. 2015, Polydoro et al. 2004). Our group has recently presented the first in vitro evidence of an association between ovarian cytotoxicity and AP-induced oxidative stress in rat's ovaries (Elmorsy and Smith 2015).

In the current study, we aimed to validate our previous in vitro results by conducting an in vivo animal study investigating the effects of two commonly used APs including HAL and CLZ on ovarian mitochondrial complexes I and III and markers for oxidative stress. We have also evaluated the underlying ovarian histopathological changes associated with the observed biochemical changes. A female albino rat model was used to test this hypothesis.

\section{Methods}

\section{Drugs and chemicals}

Clozapine $100 \mathrm{mg}$ tablets were obtained from Copad Pharma (Cairo, Egypt). Haloperidol $5 \mathrm{mg}$ tablets (Halonace) were obtained from Kahira Pharmaceuticals (Cairo, Egypt). Both clozapine and haloperidol tablets were dissolved in distilled water. For immunohistochemistry studies, mouse monoclonal Anti-Ki-67 (Clone GM010) and anti-P53 (Clone BP-53-12) were obtained from Genemed Biotechnologies Inc. (South San Francisco, CA 94080, USA). Unless otherwise specified, all other chemicals used in this study were obtained from Sigma-Aldrich (Poole, UK).

\section{Animal protocol}

Thirty adult female Wistar albino rats were used in this study. Their weights ranged between 180 and $200 \mathrm{~g}$. The rats were housed in standard polypropylene cages ( 5 rats per cage) and kept at $22 \pm 3{ }^{\circ} \mathrm{C}$ and under humidity (30-40\%) with $12: 12$-h light-dark cycles and with full access to water and food. All rats' experimental protocols and procedures were approved by the institutional review board (IRB), Faculty of Medicine, University of Mansoura (Ref: R.18.03.110).
Rats were divided into three groups of ten. The first group received distilled water and served as a control group. The second group received haloperidol (HAL) $(2 \mathrm{mg} / \mathrm{kg} / \mathrm{day})$ and the third received clozapine (CLZ) $(20 \mathrm{mg} / \mathrm{kg} /$ day) by oral gavages for 28 days. These doses were based on the study by Schleimer et al. (2005) who showed the effectiveness of this dosing in simulating clinical setting in human when administered orally in rats. On the next day after the final dose, rats were anesthetized with ether. Blood samples were taken from their hearts, centrifuged and the serum was collected. Both ovaries of each animal were excised. The right ovary was used for histopathological studies and the left one was used for biochemical investigations.

\section{Isolation of mitochondria}

The whole ovary was homogenized in $0.23 \mathrm{M}$ mannitol, $0.07 \mathrm{M}$ sucrose, $1 \mathrm{mM}$ EDTA, and $10 \mathrm{mM}$ TrisHCl, $\mathrm{pH}$ 7.4, at a ratio of $9 \mathrm{ml}$ of homogenization medium to $1 \mathrm{~g}$ of tissue, in a Potter homogenizer with a Teflon pestle. The homogenate was centrifuged at $700 \mathrm{~g}$ then at $8000 \mathrm{~g}$ (10 $\mathrm{min}$ for each) to precipitate mitochondria. Then, mitochondria were washed (Spinazzi et al. 2012). Protein was quantified in the mitochondrial suspensions according to the Bradford method (Bradford 1976), and the suspension was frozen in liquid nitrogen and kept at $80{ }^{\circ} \mathrm{C}$. Mitochondrial samples were twice frozen and thawed to disrupt the mitochondrial membrane just before use.

\section{Mitochondrial complexes I and III assay}

For complex I assay, following Janssen et al. (2007), dichlorophenolindophenol (DCIP) was used as a terminal electron acceptor. Complex I oxidizes NADH, and the electrons produced reduce the artificial substrate decylubiquinone that subsequently delivers the electrons to DCIP. Complex III activities were studied as mentioned before by Spinazzi et al. (2012).

\section{Lipid peroxidation products}

Lipid peroxidation was estimated calorimetrically in the ovarian tissue by quantifying thiobarbituric acid reactive substances (TBARS) according to the method of Niehaus and Samuelsson (1968). Briefly, for the estimation of TBARS, the supernatant of the tissue homogenate was treated with tertiary butanol-trichloroacetic acid-hydrochloric acid (TBA-TCA-HCl) reagent and mixed thoroughly. The mixture was kept in boiling water bath for $15 \mathrm{~min}$. After cooling, the tubes were centrifuged for $10 \mathrm{~min}$ and the supernatant taken for measurement at $535 \mathrm{~nm}$ using a UV spectrophotometer (Hitachi 912) and expressed as mM per $100 \mathrm{~g}$ tissue. 


\section{Catalase}

Following Sinha (1972) Catalase (CAT) was assayed colorimetrically at $620 \mathrm{~nm}$ and was expressed as micromoles of $\mathrm{H} 2 \mathrm{O} 2$ consumed per minute per $\mathrm{mg}$ of protein; To $0.1 \mathrm{ml}$ of the tissue homogenate $1.0 \mathrm{~mL}$ of $0.01 \mathrm{M} \mathrm{pH} 7$ phosphate buffer, and $0.4 \mathrm{~mL}$ of $2 \mathrm{M} \mathrm{H} 2 \mathrm{O} 2$ were added. The reaction was stopped by the addition of $2 \mathrm{~mL}$ of dichromate-acetic acid reagent.

\section{Super oxide dismutase}

The assay for super oxide dismutase (SOD) was based on SOD-mediated inhibition of the reduction of nitroblue tetrazolium to blue formazan by superoxide anions as described by Beauchamp and Fridovich (1971). Units of SOD activity determined were expressed in terms of milligrams of total protein (TP). The total protein in the homogenate was estimated by the Lowry method (Lowry et al. 1951).

\section{Reduced glutathione}

Reduced glutathione (GSH) was determined following Ellman (1959) and the absorbance was read at $412 \mathrm{~nm}$. The activity of GSH was expressed as nM GSH/100 $\mathrm{g}$ tissue.

\section{Histopathological studies}

The right ovary was cut into small specimens then fixed in $10 \%$ neutral buffered formalin solution, processed and paraffin blocks were prepared. The blocks were then sectioned at 5 - $\mu \mathrm{m}$ thickness in preparation for histological and immunehistochemical studies.

\section{Microscopic examination of stained sections}

The prepared 5- $\mu \mathrm{m}$ sections were stained with hematoxylin and eosin (H\&E) (Gamble 2008), periodic acid-Schiff (PAS) (Myers et al. 2008), and Masson trichrome stain (MTS) (Luna 1968).

\section{Immunohistochemistry staining of p53 and Ki-67}

The prepared 5- $\mu \mathrm{m}$ sections were taken on positive slides and immunostained using an avidin-biotin technique. Sections were deparaffinized, rehydrated, and pretreated with $0.01 \%$ hydrogen peroxide $\left(\mathrm{H}_{2} \mathrm{O}_{2}\right)$ to block the endogenous peroxidase activity. Then, sections were incubated in a $0.01-\mathrm{M}$ citrate buffer at ph 6 for $10 \mathrm{~min}$ and in ethanol for 10 min to mask the antigenic site. Microwave-assisted antigen retrieval was then performed for $20 \mathrm{~min}$. Sections were incubated overnight at $4{ }^{\circ} \mathrm{C}$ with the diluted primary antibody at dilution 1/500 and 1/100 monoclonal mouse antibodies for $\mathrm{Ki}-67$ and p53. Sections were incubated with the avidin-biotin complex (ABC) reagent for $60 \mathrm{~min}$ then in peroxidase solution for 6-10 min. Finally, hematoxylin was used as a counter stain. Immunoreactivity was visualized in the nucleus for both antigens. For the negative control slide, the specific 1ry antibody was replaced by phosphate buffer saline. Tonsil was used as a positive control for Anti-Ki-67 assays (Goncalves et al. 2017), while selective squamous cell carcinoma was used as a positive control for anti-P53 assays (Suzuki et al. 2006).

\section{Morphometric studies}

Five H\&E-stained slides from each rat group were used for follicle count. For each slide, follicles were counted in five non-overlapping high-power fields $(\times 100)$. According to Pedersen's follicular classification in rodents (Pedersen and Peters 1968), follicles were divided into three main categories: small (primordial and primary), medium (pre-antral), and large (antral or Graafian) follicles.

\section{Immunoexpression studies}

Sets of five slides from each rat group stained with different stains per set including MTS, Ki-7, and P53 were used for immunoexpression studies. Image analyses of the area\% of immunoexpression was measured for each stain in five non-overlapping high-power fields $(\times 100)$ in each slide. The slides were photographed using an Olympus digital camera (E24-10 M pixel, China) installed on an Olympus microscope with a $\times 0.5$ photo adaptor. The resulting images were analyzed with VideoTestMorphology computer software (Russia Federation) with a specific built-in routine for determining calibrated distance and area\% of immunoexpression (Sabha et al. 2008).

\section{Statistical analysis}

Statistical analysis of data was performed using GraphPad Prism (GraphPad Software Inc., San Diego, CA). Numerical data were presented as mean \pm sem and compared between the three groups using one way ANOVA with Turkey's multiple comparison posttest for comparison between each treated group and the control group. $P<0.05$ was considered significant.

\section{Results}

\section{Biochemical assays}

While serum prolactin concentration was significantly $(p<0.001)$ higher in the HAL group compared with the control group (Fig. 1a), it was not significantly different in the CLZ 
Fig. 1 The effect of 28-day treatment of Wister rats with clozapine and haloperidol on serum prolactin levels (a), ovarian mitochondrial complexes I and III (b, c) and ovarian oxidative stress markers (TBARS, SOD, CAT, and GSH) (d-g) compared with control rats. Data were expressed as mean \pm sem and compared between the three groups using one-way ANOVA. Turkey's multiple comparison post-test was used for comparison between each treated group and the control group. $P<0.05$ was considered significant. The exact $P$ values for ANOVA are shown and the $p$ values for the post-test are presented as (*) Double asterisks indicate $p<0.01$; triple asterisks indicate $p<0.001$ Abbreviations: CLZ, clozapine; HAL, haloperidol TBARS, thiobarbituric acid reactive substances; $\mathrm{SOD}$, super oxide dismutase; CAT, catalase; GSH, reduced glutathione
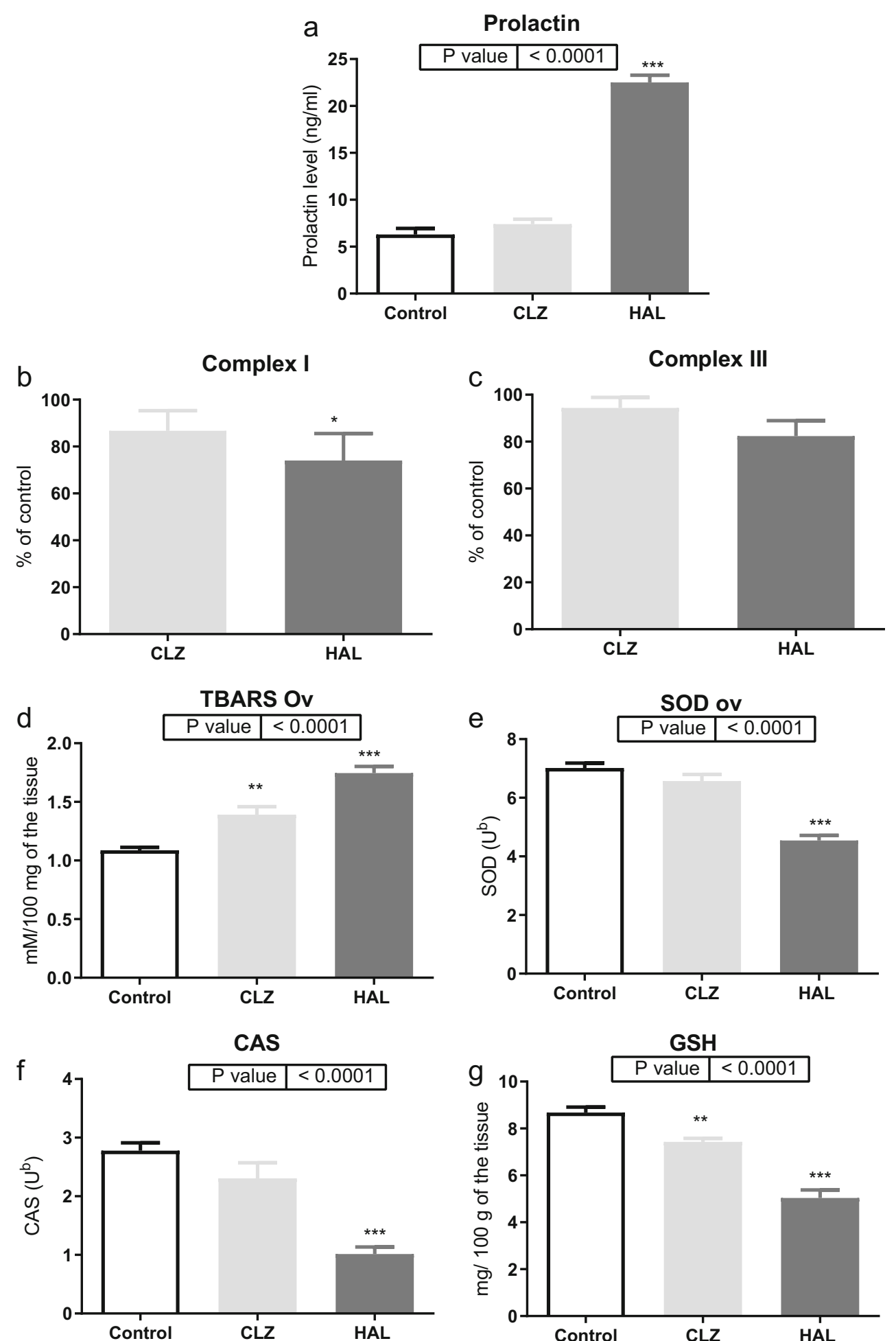

versus the control group (Fig. 1a). Both HAL and CLZ significantly $(p<0.001)$ inhibited complex I activity, but only HAL significantly $(p<0.05)$ inhibited complex III activity (Fig. 1b, c).

Lipid peroxidation studies showed a significant increase of TBARS in both HAL- and CLZ-treated rats $(p<0.001$ and $p<0.01$ respectively) (Fig. $1 \mathrm{~d}$ ). Also, there was a significant $(p<0.001)$ reduction in SOD, CAT, and GSH in the HAL-treated ovaries. On the other hand, CLZtreated rats showed a significant decrease in SOD and GSH ( $p<0.001$ and $p<0.01$, respectively) with no change in CAT in comparison with controls (Fig. 1e, f and g). 


\section{Histopathological studies}

\section{Microscopic examination of stained sections}

Examination of H\&E-stained sections of ovaries obtained from the control rats revealed a normal ovarian histological structure with an outer simple cubical epithelium, an ovarian cortex characterized by multiple follicles in various stages of development, and a central medulla made of the vascularized ovarian stroma (Fig. 2a-d). H\&E-stained sections of ovaries obtained from CLZ-treated rats revealed multiple cystic atretic follicles with degenerated ova and vacuolation of cells in some of them. Antral follicles were characterized by increased apoptotic cells, some of which were detached into the antrum. In addition, dilated and congested vessels were observed in the ovarian medulla (Fig. 2e-g). H\&E-stained sections of ovaries from HAL-treated rats revealed absence of growing follicles, increased large corpora lutea, and increased atretic follicles (Fig. 2h, i).

PAS-stained sections of control rats demonstrated a strong positive PAS reaction in the zona pellucidum of the growing follicle and moderate reaction of the healthy ova (Fig. 3a). While PAS-stained sections of CLZ-treated rats showed a cystic follicle with degenerated zona pellucidum and oocyte (Fig. 3b), PAS-stained sections of HAL-treated rats revealed degenerated zona pellucidum and degenerated oocyte (Fig. 3c).

MTS-stained sections of control rats revealed the presence of few collagen fibers mainly around the blood vessels and around the corpus luteum (Fig. 3d). MTS-stained sections of CLZtreated animals showed a slight increase in collagen fibers mainly around the atretic follicles (Fig. 3e). MTS-stained sections of HAL-treated rats revealed areas with extensive deposition of collagen fibers around the corpora lutea (Fig. 3f).

\section{Immunohistochemistry of p53 and Ki-67}

Ki-67-immunostained ovarian sections of control rats showed strong and discrete staining of the nuclei of the majority of granulosa and theca cells of growing and Graafian follicles. Cells of newly formed corpora lutea were Ki-67 positive while most cells of older ones were negatively stained (Fig. 4a). Ki67-immunostained sections of CLZ-treated rats showed negatively stained cystic atretic follicles and corpora lutea (Fig. 4b). Ki-67-immunostained sections of HAL-treated rats showed negatively stained atretic follicles and moderately stained corpora lutea (Fig. 4c).

P53-immunostained ovarian sections of control rats showed negatively stained cell nuclei of the majority of granulosa and theca follicular cells of growing follicles as well as cells of newly formed corpora lutea, while most cells of older corpora lutea were positively stained (Fig. 4d). P53-immunostained sections of CLZ-treated rats showed positively stained cell nuclei of the majority of cystic atretic follicles and cells of corpora lutea (Fig. 4e). P53-immunostained sections of the HAL group showed extensive staining of the cell nuclei of the atretic follicles, while the cells of corpora lutea were moderately stained (Fig. 4f).

\section{Immunoexpression study}

Immunoexpression study of the area\% of the collagen fibers measured in MTS sections of the treated rats' ovaries showed a significant increase in both HAL- and CLZ-treated rats as compared with controls ( $p<0.001$ and $p<0.01$, respectively) (Fig. 5f). Similarly, area\% of the P53-immunostained sections revealed a significant $(p<0.001)$ increase in both HAL- and CLZ-treated rats as compared with controls. While area\% of the Ki-67-immunostained sections showed a significant $(p<$ 0.001) decrease in both HAL- and CLZ-treated rats in comparison with controls (Fig. 5h).

\section{Morphometric studies}

Regarding numbers of follicles, the morphometric studies showed a significant $(p<0.001)$ decrease in the number of healthy follicles (small-, medium-, and large-sized follicles) and a significant $(p<0.001)$ increase of atretic follicles in HAL- and CLZ-treated rats versus the control rats (Fig. 5ac). HAL-treated rats exhibited a significant $(p<0.01)$ increase in the count of corpora lutea with no change in cystic follicles (Fig. 5d, e), whereas the CLZ group showed a significant $(p<0.001)$ decrease in corpora lutea and a significant $(p<0.001)$ increase in cystic follicles compared with the controls (Fig. 5d,e).

\section{Discussion}

In this in vivo animal study, we have for the first time investigated the effects of two commonly used APs including HAL and CLZ on the rat's serum prolactin level, ovarian mitochondrial complexes I and III, and markers for oxidative stress as possible mechanisms of AP-induced ovarian dysfunction. We have also examined the underlying ovarian histopathological changes associated with the observed AP-induced biochemical changes. The results revealed that prolactin was increased only in HAL-treated rats, but remained unchanged in the CLZ group supporting our hypothesis that hyperprolactinemia alone cannot explain all reproductive adverse effects of APs. While HAL significantly inhibited both mitochondrial complexes, CLZ inhibited complex I only. Biochemical studies showed that both HAL and CLZ induced oxidative stress. Our histopathological data showed evidence of ovarian tissue damage characteristic of oxidative stress. All these findings together support the hypothesis that AP-induced oxidative 

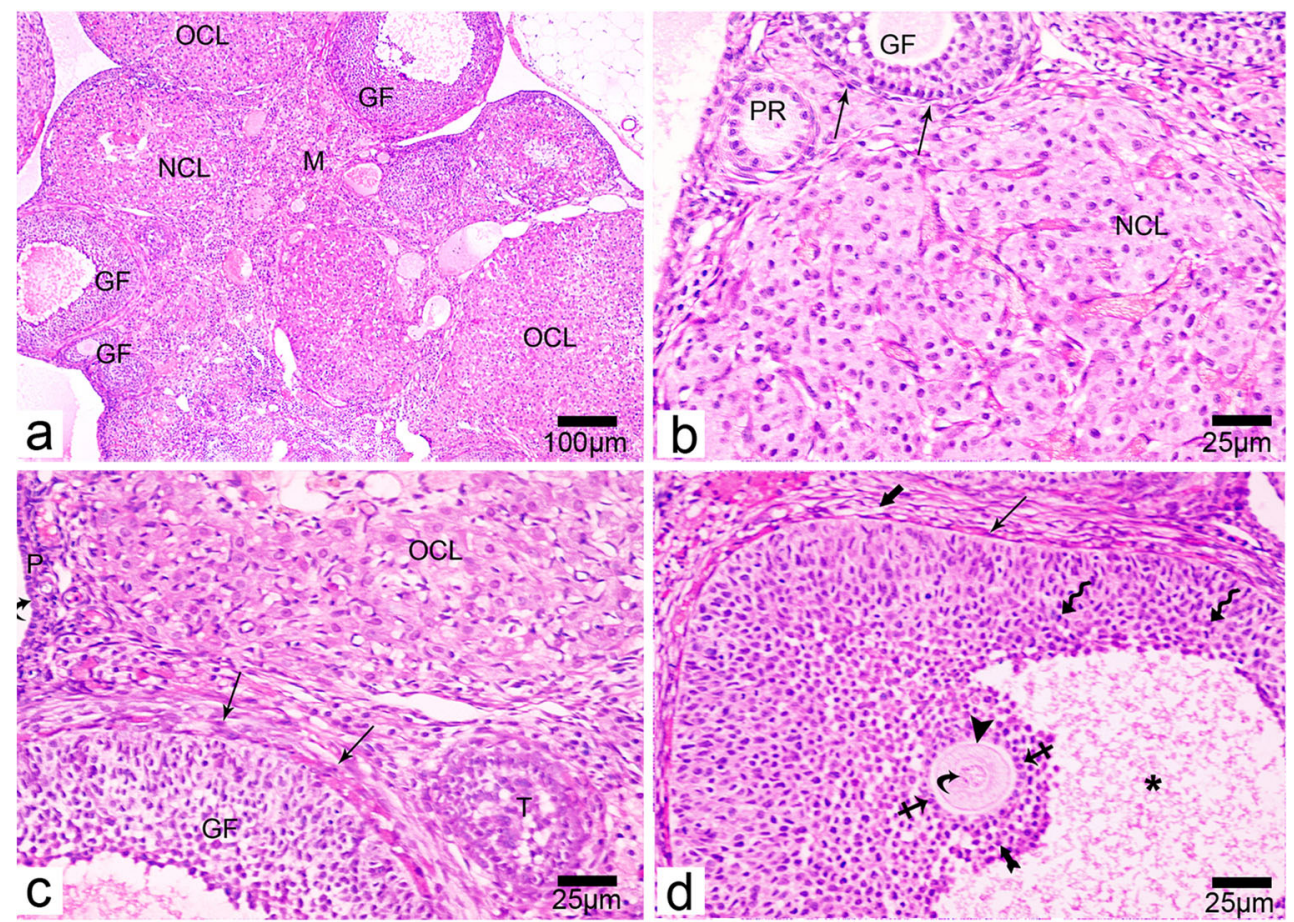

C
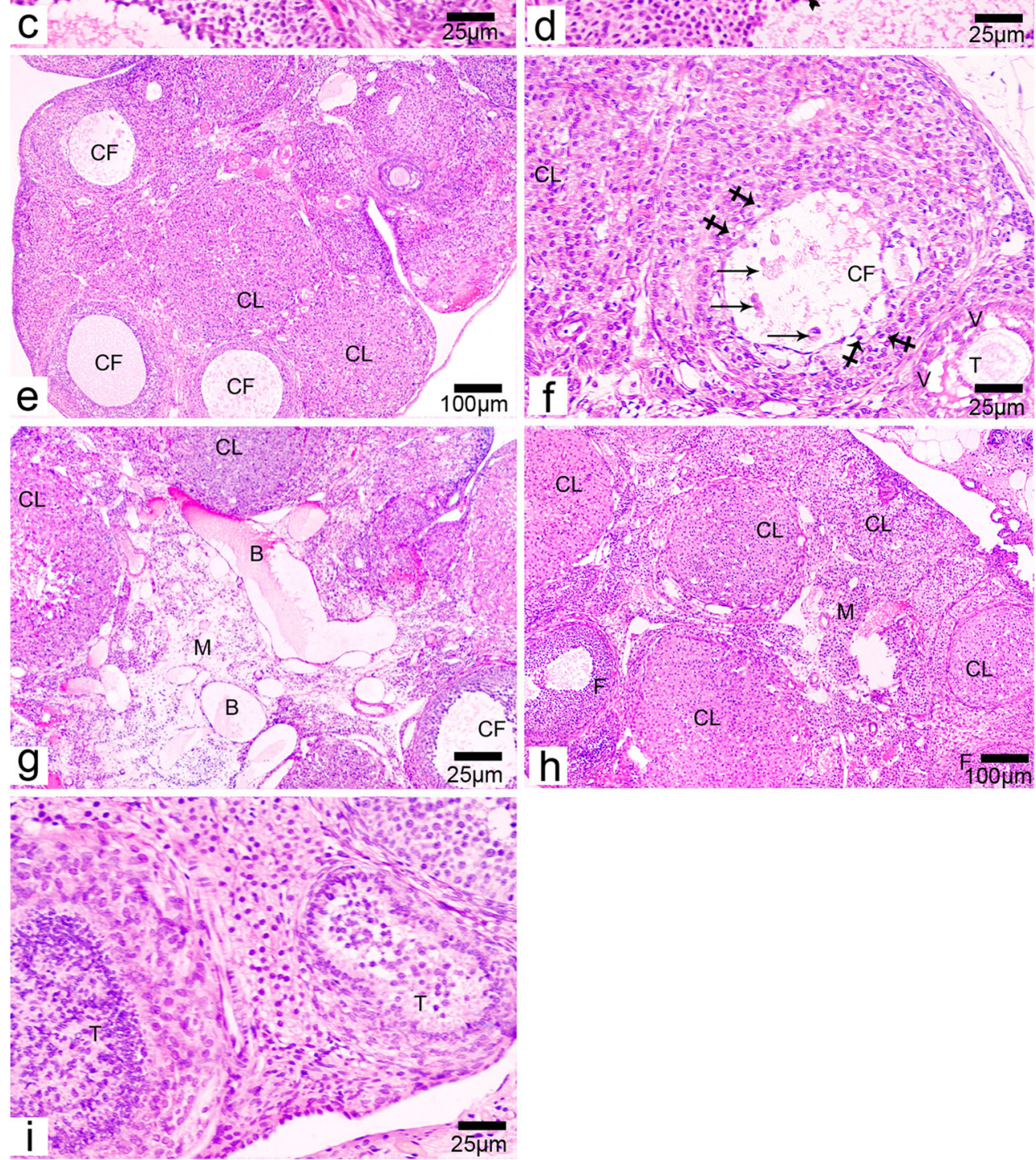
4 Fig. 2 Photomicrographs of H\&E-stained rat ovarian sections. Control ovarian sections showing multiple growing follicles (GF) in various stages of development, newly formed corpus luteum (NCL) with small spindle-shaped basophilic cells, and previously formed corpus luteum (OCL) with foamy and eosinophilic cells, vascularized medulla (M), primary follicle (PR), atretic follicle (T), mature follicle with oocyte (curved arrow), ZP (arrow head), corona radiate (crossed arrow), cumulus oophorus (tailed arrow), granulosa cells vesicular nuclei and vacuolated acidophilic cytoplasm (zigzagged arrow), theca interna (arrow), theca externa (thick arrow), and antral cavity (asterisk) (a-e). Note the welldeveloped theca layer (arrow) and the simple cubical surface epithelium (black curved arrow). Ovarian sections from CLZ-treated rats showing multiple cystic atretic follicles (CF), corpora lutea (CL), multiple vacuoles (v) of degenerated granulosa cells, dilated congested vessels (B) in the ovarian medulla (M), detached apoptotic granulosa cells and desquamated into CF antrum (arrow), condensed nuclei surrounded by vacuolated cytoplasm (crossed arrow) (f, g). Ovarian sections from HAL-treated rats showing multiple large and active corpora lutea (CL) present in cortical and medullary regions, multiple atretic follicles $(\mathrm{F})$, and atretic growing follicles (T) without observable ovum (h, i). Abbreviations: CLZ, clozapine-treated group; Con, control group; HAL, haloperidol-treated group stress in the ovaries may explain the ovarian dysfunction observed in women receiving APs.

Concerning the dosages of HLA and CLZ, we have chosen the same dosages used by Schleimer et al. (2005) who have reported that 2-4 weeks of daily oral administration of HAL $(2 \mathrm{mg} / \mathrm{kg} / \mathrm{d})$ and CLZ $(20 \mathrm{mg} / \mathrm{kg} / \mathrm{d})$ were effective in inducing drug-related extrapyramidal side effects in rats similar to toxicity in humans. We believe that these doses are also expected to induce reproductive toxicity via a mechanism of oxidative stress, which is the same mechanism of extrapyramidal side effects.

Our prolactin data are in agreement with several previous in vivo human studies reporting an increase in the prolactin level in women receiving conventional APs due to dopamine receptor (D2) antagonist effect (Kinon et al. 2003; Bargiota et al. 2013). Our data are also consistent with Melkersson (2005) who reported no increase in the prolactin level in 28 women receiving CLZ.
Fig. 3 A photomicrograph of PAS- and MTS-stained ovarian sections. PAS-stained section for control rat's ovary revealing a strong +ve PAS reaction in the zona pellucidum (arrow) of the growing follicle with moderate reactivity of the healthy ova (crossed arrow) (a). PAS-stained section for clozapine-treated rat illustrating a cystic follicle with degenerated zona pellucidum (arrow) and degenerated oocyte (crossed arrow) (b). PAS-stained section for haloperidol-treated rat revealing degenerated zona pellucidum (arrow) and degenerated oocyte (crossed arrow) (c). MTS-stained section for control rats revealing the presence of few collagen fibers mainly around the blood vessels and around the corpus luteum (arrows) (d). MTS-stained section for clozapine-treated rats with a slight increase in collagen fibers mainly around the atretic follicles (arrows) (e). MTS-stained section for haloperidol-treated rats revealing areas with extensive deposition of collagen fibers around the corpora lutea (arrows) (e). Abbreviations: PAS, periodic acid-Schiff; MTS, Masson trichrome stain
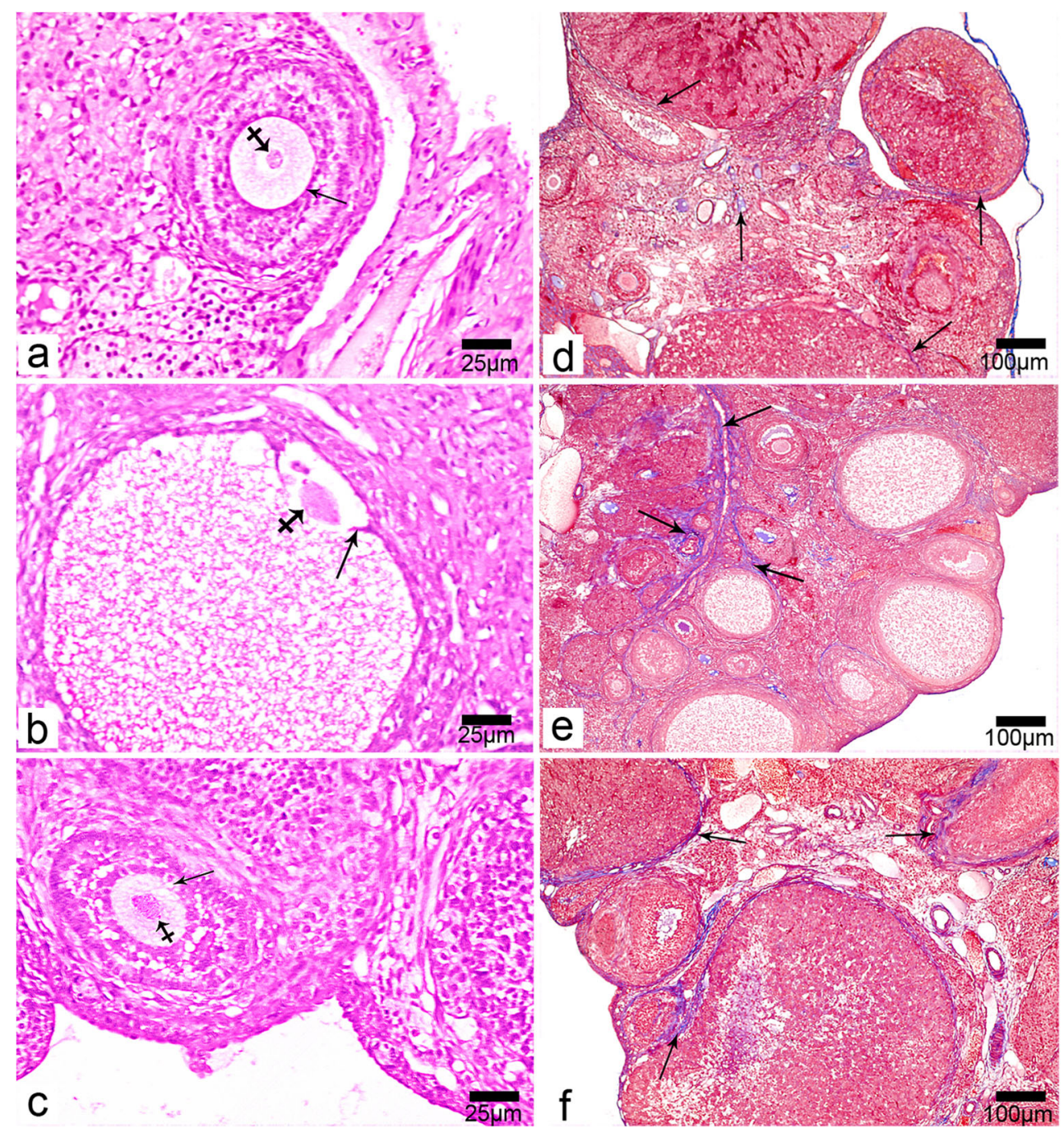

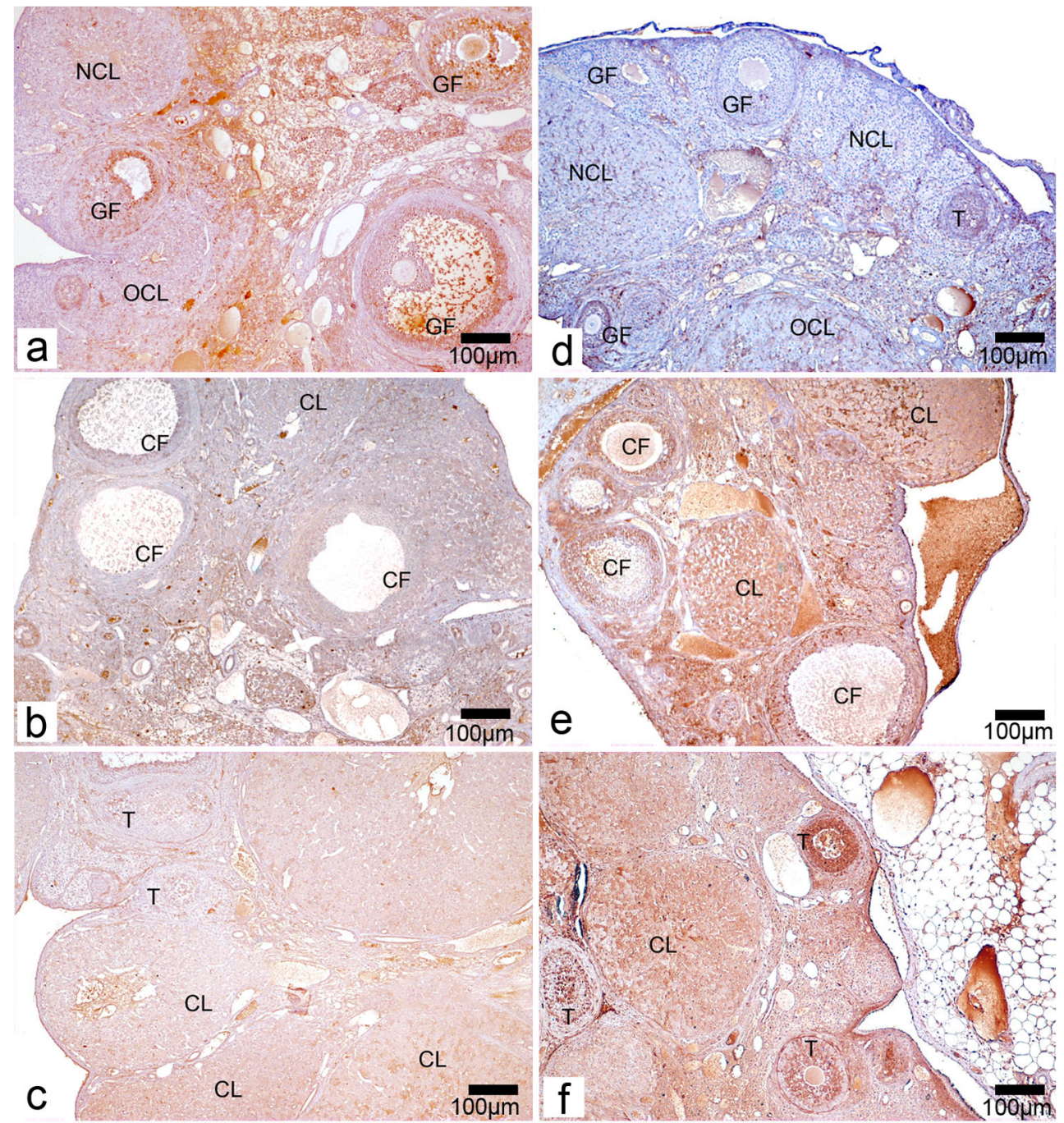

Fig. 4 A photomicrograph of the ovarian sections of the studied groups stained with immunohistochemical staining for Ki-67 and P53. Ki-67immunostained sections of the control group showed strong and discrete staining of the cell nuclei (a). In the follicular wall of growing and Graafian follicles (GF), the majority of granulosa and theca cells were positively stained. Cells of newly formed corpus luteum (NCL) were Ki67 positive while most cells of previously formed corpora lutea were negatively stained (OCL). Ki-67-immunostained sections of clozapinetreated animals showed negatively stained cystic atretic follicles (CF) with negatively stained corpus luteum (CL) (b). Ki-67-immunostained sections of haloperidol-treated animals showed negatively stained atretic follicles (T) and moderate stained corpora lutea (CL) (c). A photomicrograph of the ovarian sections of the studied groups stained with

The findings of the current study regarding the effect of both APs on ovarian mitochondrial complexes are in accordance with previous studies on non-reproductive organs. In brain tissue, Balijepalli et al. (2001) reported that a single HAL dose in mice led to a $41 \%$ inhibition of complex I activity in the striatum and a $26 \%$ decrease in the midbrain only 30 mins after injection, but with no inhibition in the frontal cortex or hippocampus. On the other hand, Burkhardt et al. (1993) reported that CLZ treatment immunohistochemical staining (p53). P53-immunostained sections of the control group showed negatively stained cell nuclei of the majority of granulosa and theca follicular cells of growing follicles (GF) (d). Cells of newly formed corpus luteum (NCL) were negatively stained while most cells of previously formed corpora lutea (OCL) were positively stained. Note the presence of positively stained atretic follicle (T). P53immunostained sections of clozapine-treated animals showed positively stained cell nuclei of the majority of cystic atretic follicles (CF) (e). Cells of corpus luteum (CL) were also positively stained. P53-immunostained sections of haloperidol-treated animal showed extensive staining of the cell nuclei of the atretic follicles (T) (f). Cells of corpus lutea were moderate stained $(\mathrm{CL})$

in rats led to a $16 \%$ decrease in complex I activity in the frontal cortex and a $15 \%$ decrease in the hippocampus, but only after 90 days of exposure. In rat liver mitochondria, Modica-Napolitano et al. (2003) showed that complex I is inhibited by HAL, but not by CLZ.

In humans, HAL and CLZ, at therapeutic levels, were shown to inhibit complex I of the mitochondrial respiratory chain in the peripheral blood mononuclear cells of psychotic patients (Casademont et al. 2007). The presence of 
mitochondrial dysfunction in patients with schizophrenia limits the researchers' ability to assess the effect of APs on complexes I and III (Karry et al. 2004).

The mechanism of HAL-induced inhibition of complex I has been postulated by Subramanyam et al. (1991). HAL can undergo oxidation giving rise to the metabolite HAL pyridinium ion, which resembles the active toxic metabolite of MPTP, which is a selective inhibitor of complex I (Subramanyam et al. 1991). AP-induced inhibition of mitochondrial complexes I and III has been suggested as a possible mechanism of oxidative stress in ovarian tissue. Inhibition of complexes I and III could lead to the release of electrons of $\mathrm{NADH}$ and FADH, which unite with oxygen molecules forming superoxide radical with subsequent formation of ROS (Fato et al. 2009).

Our findings in relation to HAL and oxidative stress are in agreement with earlier studies, which reported changes in levels of some antioxidant enzyme activity in rat brains after chronic treatment with typical antipsychotics (Pillai et al. 2007). On the other hand, literature data regarding CLZ and oxidative stress are conflicting. In accordance with our data, Reinke et al. (2004) showed that CLZ can induce oxidative stress in the brains of rats after 28 days of CLZ $25 \mathrm{mg} / \mathrm{kg} /$ day (the same dose as ours). In contrast to our findings, Parikha et al. (2003) showed that there was no significant oxidative stress in the brains of rats receiving CLZ (20 mg/kg/day) for up to 90 days. Recently, Abdel-Wahab and Metwally (2015) reported that CLZ-induced oxidative stress may play a role in cardiotoxicity among rats receiving CLZ at concentration range of $20-50 \mathrm{mg} / \mathrm{kg} /$ day. They speculated that the CLZ-induced decrease in antioxidant enzyme activities including CAT, SOD, and GSH may be responsible for the inadequacy of combating ROS-mediated cell damage.

It is well established that ROS and oxidative stress have a major effect on female reproduction and ovulation (Agarwal et al. 2012). Oxidative stress occurs when formation of ROS blows the capacity of the cells to protect themselves from increased ROS via sufficient levels of antioxidant enzymes, which are important for ovarian function (Tilly and Tilly 1995). Our study showed that both HAL and CLZ were associated with the increase in the TBARS level with decreased SOD, CAS, and reduced GSH supporting our hypothesis that APs induce oxidative stress.

Our HAL histological findings showing large corpora lutea and multiple atretic follicles without follicular growth are consistent with ovarian changes known to be induced by hyperprolactinemia (Kunimatsu et al. 2010). Several previous studies have shown hyperprolactinemia to stimulate and maintain corpora lutea in rodents due to the luteotropic activity of prolactin (Bachelot and Binart 2007; Bowen et al. 1996; Goyeneche et al. 2003; Tesone et al. 1984).

Our CLZ-related ovarian histopathological changes including multiple cystic atretic follicles, degenerated ova, degenerated zona pellucida, vacuolation of granulosa cells, dilated and medullary congestion, and fibrosis are consistent with known effects of oxidative stress as previously reported (Alchalabi et al. 2016; Saber et al. 2011; Royce et al. 2007; Balakrishnan et al. 2013). Alchalabi et al. (2016) described ovarian histological changes in rats subjected to oxidative stress induced by electromagnetic waves. These changes included vacuolation in interstitial, granulosa and luteal cells in the ovaries, disorientation of corona radiata, disruption and thinning of the zona pellucida, and cellular nucleus changes. Saber et al. (2011) reported topsin-induced histological changes in rat's ovary, which are similar to our CLZ histological findings and explained that all these changes are caused by oxidative stress. These changes include congested stromal blood vessels, large number of atretic follicles, abnormal Graafian follicles with enlarged antrum, and degenerated zona pellucida and cumulus oophorus. Furthermore, our CLZ histological data agree with previous studies reporting that oxidative stress in chromium-treated rats revealed ovarian medullary vessel congestion, follicle degeneration and necrosis, and fibrosis (Royce et al. 2007 and Balakrishnan et al. 2013).

The current study also revealed increased apoptosis in follicular cells in CLZ- and HAL-treated rats. This can be explained by impairment of the mitochondrial respiratory chain. This is supported by a previous study reporting that a $25 \%$ decrease in complex I activity resulted in a 35\% decrease in ATP and mitochondrial respiration, thus severely impairing energy production with subsequent apoptosis (Davey et al. 1998). In addition, Miyamoto et al. (2010) reported that increased ROS are important in triggering apoptosis in granulosa cells of growing follicles. Furthermore, GSH depletion was shown to increase apoptotic antral follicles (Nakamura et al. 2011).

The vacuolation of granulosa cells observed in CLZ-treated rats may be caused by accumulated lipids that dissolved during the preparation of hematoxylin and eosin stain slides. However, it could also be caused by disordered steroidogenesis as previously reported by Patil et al. (1999) who found an increase in the ovarian cholesterol level due to inhibition of steroidogenesis in nicotine-treated rats.

Antigen $\mathrm{Ki}-67$ is a nuclear protein that is associated with and may be necessary for cellular proliferation and ribosomal RNA synthesis (Bullwinkel et al. 2006). In the present study, HAL- and CLZ-treated rats' ovaries exhibited a decrease in Ki-67 immunostaining suggesting inhibited cellular proliferation. The role of oxidative stress in this inhibition is controversial. While some studies showed that oxidative stress can inhibit cell proliferation (Miethling-Graff et al. 2014; Carrasco-Torres et al. 2017), others found oxidative stress to increase cell proliferation (Burdon et al. 1990; Galli et al. 2005). Another study showed oxidative stress to reduce the cellular proliferation when hydrogen peroxide levels are high, but promote cellular proliferation when hydrogen peroxide levels are low (Burdon et al. 1989). 
a

Small and medium healthy follicles
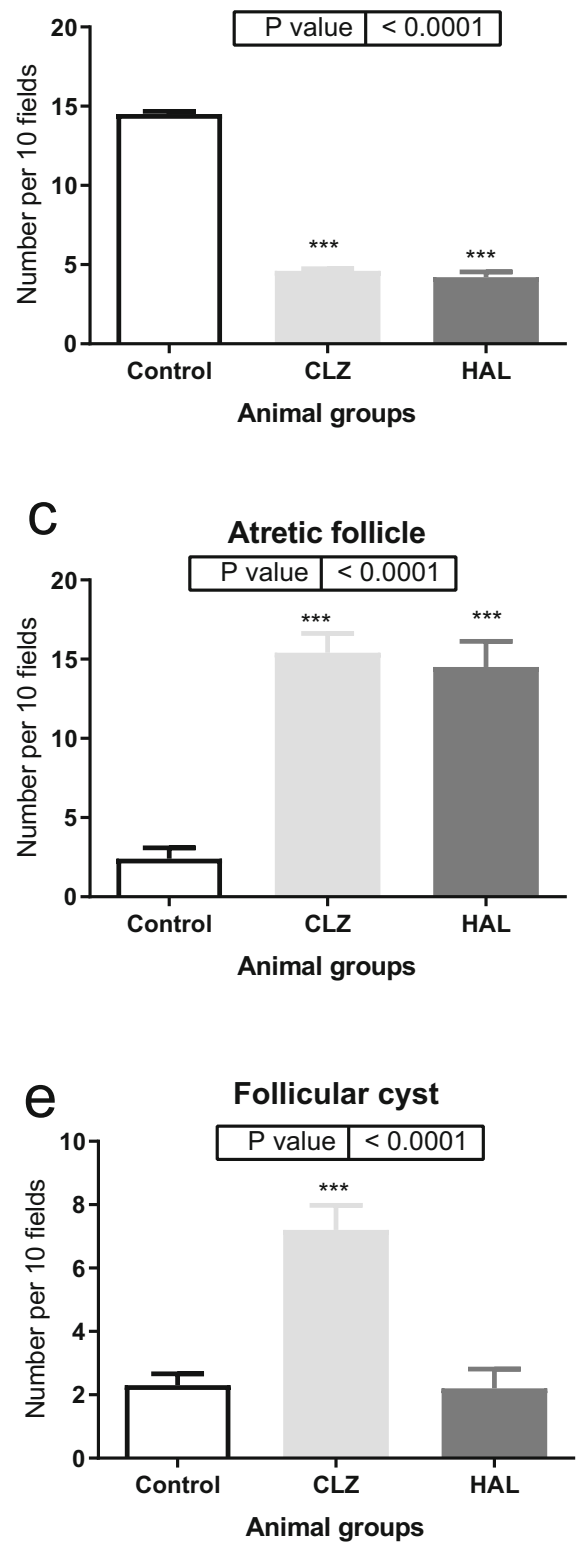

g

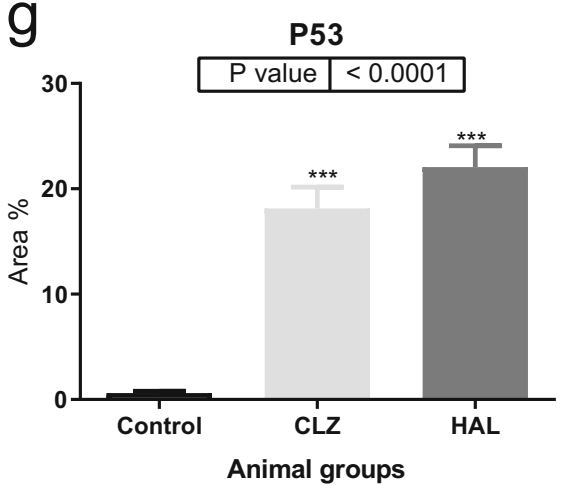

b

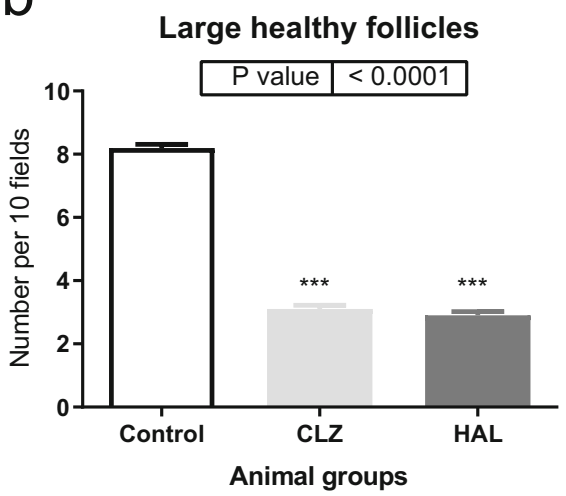

d

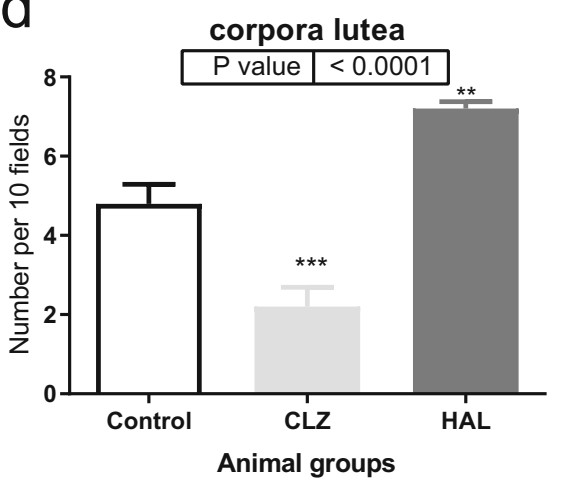

f

MTS

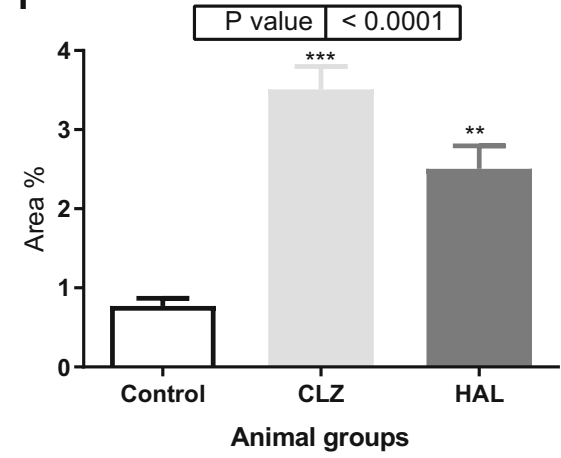

h

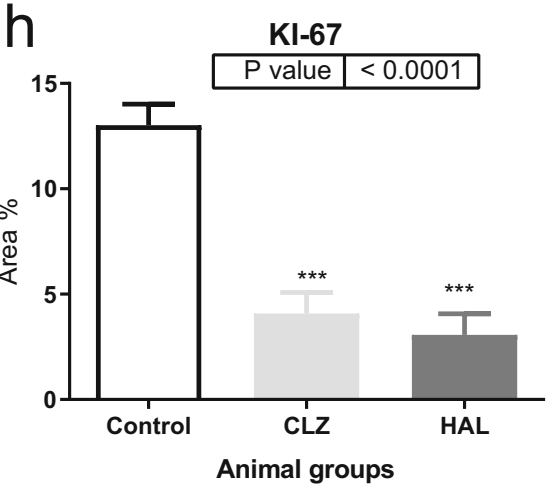


Fig. 5 The morphometric study of effect of clozapine and haloperidol on treated rats' ovaries corpora lutea (a), large healthy follicles (b), follicular cysts (c), atretic follicles (d), medium- and small-sized healthy follicles (e), area\% of immunoexpression of Masson trichrome staining (f), Ki-67 (g), and P53 (h). Data are expressed as mean \pm sem and compared between the three groups using one-way ANOVA. Turkey's multiple comparison post-test was used for comparison between each treated group and the control group. $P<0.05$ was considered significant. The exact $P$ values for ANOVA are shown and the $p$ values for the post-test are presented as (*) The double asterisks indicate $p<0.01$ and the triple asterisks indicate $p<0.001$ Abbreviations are as in Fig. 1

On the other hand, our study showed increased p53 immunostaining in ovaries of HAL- and CLZ-treated rats. The tumor suppressor protein p53 activation is known to cause cell cycle arrest and apoptosis (Chen 2016). It is highly inducible by many stress signals such as oxidative DNA damage (Liu et al. 2014).

Our findings provide important in vivo evidence of APinduced oxidative stress as an important mechanism of ovarian cytotoxicity with subsequent reproductive dysfunctions. Further research is needed to investigate the potential role of antioxidants in preventing and reversing the ovarian cytotoxicity induced by APs. Other therapeutics that may have a prophylactic effect and could be investigated include an alternative respiratory substrate (such as hydroxyl butyrate) or vitamin (such as coenzyme Q).

Finally, our data showed that CLZ as a typical AP is less toxic than HAL. This difference could be related to several factors, such as the differences in dopamine receptor affinity or differences in toxicity of its metabolites. Clearly, our results do not explore the explanations to these differences, but further studies will address these issues.

In conclusion, this in vivo animal study provides compelling biochemical and histopathological evidence of a role for AP-induced oxidative stress in the causation of AP-induced ovarian dysfunction. This paves the way to the development of effective therapeutics targeting the underlying mechanisms to prevent the destressing reproductive adverse effects.

Acknowledgments The authors are indebted to the Staff at the Medical Experimental Research Center of Mansoura University for their support and advice.

\section{Compliance with ethical standards}

Conflict of interest The authors declare that they have no conflict of interest.

\section{Informed consent N/A}

Ethical approval All applicable international, national, and/or institutional guidelines for the care and use of animals were followed. All rats' experimental protocols and procedures were approved by the institutional review board (IRB), Faculty of Medicine, University of Mansoura (Ref: R.18.03.110).
Open Access This article is distributed under the terms of the Creative Commons Attribution 4.0 International License (http:// creativecommons.org/licenses/by/4.0/), which permits unrestricted use, distribution, and reproduction in any medium, provided you give appropriate credit to the original author(s) and the source, provide a link to the Creative Commons license, and indicate if changes were made.

\section{References}

Abdel-Wahab BA, Metwally ME (2015) Clozapine-induced cardiotoxicity: role of oxidative stress, tumour necrosis factor alpha and NF- $\kappa \beta$. Cardiovasc Toxicol 15:355-365

Agarwal A, Aponte-Mellado A, Premkumar BJ, Shaman A, Gupta S (2012) The effects of oxidative stress on female reproduction: a review. Reprod Biol Endocrinol 10:49

Alchalabi AS, Rahim H, Aklilu E, Al-Sultan II, Aziz AR, Malek MF, Ronald SH, Khan MA (2016) Histopathological changes associated with oxidative stress induced by electromagnetic waves in rats' ovarian and uterine tissues. Asian Pac J Reprod 5:301-310

Bachelot A, Binart N (2007) Reproductive role of prolactin. Reproduction 133:361-369

Balakrishnan R, Kumar CS, Rani MU, Kavita K, Boobalan G, Reddy AG (2013) Evaluation of protective action of $\alpha$-tocopherol in chromium-induced oxidative stress in female reproductive system of rats. J Nat Sci Biol Med 4:87

Balijepalli S, Kenchappa RS, Boyd MR, Ravindranath V (2001) Protein thiol oxidation by haloperidol results in inhibition of mitochondrial complex I in brain regions: comparison with atypical antipsychotics. Neurochem Int 38:425-435

Bargiota SI, Bonotis KS, Messinis IE, Angelopoulos NV (2013) The effects of antipsychotics on prolactin levels and women's menstruation. Schizophr Res Treatment. https://doi.org/10.1155/2013/ 502697

Beauchamp C, Fridovich I (1971) Superoxide dismutase: improved assays and an assay applicable to acrylamide gels. Anal Biochem 1(44):276-287

Bishnoi M, Kumar A, Chopra K, Kulkarni SK (2007) Comparative neurochemcial changes associated with chronic administration of typical and atypical neuroleptics: implication in tardive dyskinesia. Indian J Exp Biol 45:175-179

Bowen JM, Landis Keyes P, Warren JS, Townson DH (1996) Prolactininduced regression of the rat corpus luteum: expression of monocyte chemoattractant protein-1 and invasion of macrophages. Biol Reprod 54:1120-1127

Bradford MM (1976) A rapid and sensitive method for the quantitation of microgram quantities of protein utilizing the principle of protein-dye binding. Anal Biochem 72:248-254

Bullwinkel J, Baron-Lühr B, Lüdemann A, Wohlenberg C, Gerdes J, Scholzen T (2006) Ki-67 protein is associated with ribosomal RNA transcription in quiescent and proliferating cells. J Cell Physiol 206:624-635

Burdon RH, Gill V, Rice-Evans C (1989) Cell proliferation and oxidative stress. Free Radic Res Commun 7:149-159

Burdon RH, Gill V, Rice-Evans C (1990) Oxidative stress and tumour cell proliferation. Free Radic Res Commun 11:65-76

Burkhardt C, Kelly JP, Lim YH, Filley CM, Parker Jr WD (1993) Neuroleptic medications inhibit complex I of the electron transport chain. Ann Neurol 33(5):512-7

Canuso CM, Goldstein JM, Wojcik J, Dawson R, Brandman D, Klibanski A, Schildkraut JJ, Green AI (2002) Antipsychotic medication, prolactin elevation, and ovarian function in women with schizophrenia and schizoaffective disorder. Psychiatry Res 111:11-20

Carrasco-Torres G, Baltiérrez-Hoyos R, Andrade-Jorge E, Villa-Treviño S, Trujillo-Ferrara JG, Vásquez-Garzón VR (2017) Cytotoxicity, 
oxidative stress, cell cycle arrest, and mitochondrial apoptosis after combined treatment of hepatocarcinoma cells with maleic anhydride derivatives and quercetin. Oxidative Med Cell Longev 2017: 2734976

Casademont J, Garrabou G, Miró O, López S, Pons A, Bernardo M, Cardellach F (2007) Neuroleptic treatment effect on mitochondrial electron transport chain: peripheral blood mononuclear cells analysis in psychotic patients. J Clin Psychopharmacol 27:284-291

Chen J (2016) The cell-cycle arrest and apoptotic functions of p53 in tumor initiation and progression. Cold Spring Harb Perspect Med 6:a026104. https://doi.org/10.1101/cshperspect.a026104

Daniel DG, Copeland LF (2000) Ziprasidone: comprehensive overview and clinical use of a novel antipsychotic. Expert Opin Investig Drugs 9:819-828

Davey GP, Peuchen S, Clark JB (1998) Energy thresholds in brain mitochondria: potential involvement in neurodegeneration. J Biol Chem 273:753-757

El-Awdan SA, Jaleel GA, Saleh DO (2015) Alleviation of haloperidol induced oxidative stress in rats: effects of sucrose vs grape seed extract. Bull Fac Pharm, Cairo University 53:29-35

Ellman GC (1959) Tissue sulflydryl groups. Arch Biochem Biophys 82: 70-77

Elmorsy E, Smith PA (2015) Bioenergetic disruption of human microvascular endothelial cells by antipsychotics. Biochem Biophys Res Commun 460:857-862

Fato R, Bergamini C, Bortolus M, Maniero AL, Leoni S, Ohnishi T, Lenaz G (2009) Differential effects of mitochondrial complex I inhibitors on production of reactive oxygen species. Biochim Biophys Acta Bioenerg 1787:384-392

Galli A, Svegliati-Baroni G, Ceni E, Milani S, Ridolfi F, Salzano R, Tarocchi M, Grappone C, Pellegrini G, Benedetti A, Surrenti C (2005) Oxidative stress stimulates proliferation and invasiveness of hepatic stellate cells via a MMP2-mediated mechanism. Hepatology 41:1074-1084

Gamble M (2008) Haematoxyline and eosin. In: Bancroft JD, Gamble M (eds) Theory and practice of histological techniques, 6th edn. Churchill Livingstone, New York, pp 121-136

Goncalves R, DeSchryver K, Ma C, Tao Y, Hoog J, Cheang M, Crouch E, Dahiya N, Sanati S, Barnes M, Sarian LO (2017) Development of a Ki-67-based clinical trial assay for neoadjuvant endocrine therapy response monitoring in breast cancer. Breast Cancer Res Treat 165: 355-364

Goyeneche AA, Deis RP, Gibori G, Telleria CM (2003) Progesterone promotes survival of the rat corpus luteum in the absence of cognate receptors. Biol Reprod 68:151-158

Halbreich U, Kinon BJ, Gilmore JA, Kahn LS (2003) Elevated prolactin levels in patients with schizophrenia: mechanisms and related adverse effects. Psychoneuroendocrinology 28:53-67

Janssen AJ, Trijbels FJ, Sengers RC, Smeitink JA, Van den Heuvel LP, Wintjes LT, Stoltenborg-Hogenkamp BJ, Rodenburg RJ (2007) Spectrophotometric assay for complex I of the respiratory chain in tissue samples and cultured fibroblasts. Clin Chem 53:729-734

Karry R, Klein E, Ben Shachar D (2004) Mitochondrial complex I subunits expression is altered in schizophrenia: a postmortem study. Biol Psychiatry 55:676-684

Kinon BJ, Gilmore JA, Liu H, Halbreich UM (2003) Prevalence of hyperprolactinemia in schizophrenic patients treated with conventional antipsychotic medications or risperidone. Psychoneuroendocrinology, 28:55-68

Kumar KS, Abhishek P, Kumar PS, Prashant T (2013) Study of oestrus cycle periodicity and oogenesis of adult albino rats: response to hyperprolactinaemia induced by haloperidol. Asian Pac J Reprod 2:99-104

Kunimatsu T, Kimura J, Funabashi H, Inoue T, Seki T (2010) The antipsychotics haloperidol and chlorpromazine increase bone metabolism and induce osteopenia in female rats. Regul Toxicol Pharmacol 58:360-368

Lin ED, Lee NJ, Slack K, Karl T, Duffy L, Brien EO, Matsumoto I, Dedova I, Herzog H, Sainsbury A (2006) Distinct endocrine effect of chronic haloperidol or risperidone administration in male rats. Neuropharmacology 51:1129-1136

Liu B, Bhatt D, Oltvai ZN, Greenberger JS, Bahar I (2014) Significance of $\mathrm{p} 53$ dynamics in regulating apoptosis in response to ionizing radiation, and polypharmacological strategies. Sci Rep 4:6245

Lowry OH, Rosebrough NJ, Farr AL, Randall RJ (1951) Protein measurement with the Folin phenol reagent. J Biol Chem 193:265-275

Luna LG (1968) Manual of histologic staining methods of the armed force institute of pathology, 3rd edn. New York, McGraw-Hill

Majumdar A, Manga NS (2013) Hyperprolactinemia. J Human Reprod Sci 6:168-175

Martins MR, Petronilho FC, Gomes KM, Dal-Pizzol F, Streck EL, Quevedo J (2008) Antipsychotic-induced oxidative stress in rat brain. Neurotox Res 13:63-69

Melkersson K (2005) Differences in prolactin elevation and related symptoms of atypical antipsychotics in schizophrenic patients. J Clin Psychiatry 66:761-767

Miethling-Graff R, Rumpker R, Richter M, Verano-Braga T, Kjeldsen F, Brewer J, Hoyland J, Rubahn HG, Erdmann H (2014) Exposure to silver nanoparticles induces size-and dose-dependent oxidative stress and cytotoxicity in human colon carcinoma cells. Toxicol in Vitro 28:1280-12890

Miyamoto K, Sato F, Kasahara E, Jikumaru M, Hiramoto K, Tabata H, Katsuragi M, Odo S, Utsumi K, Inoue M (2010) Effect of oxidative stress during repeated ovulation on the structure and functions of the ovary, oocytes, and their mitochondria. Free Radic Biol Med 49: 674-681

Modica-Napolitano JS, Lagace CJ, Brennan WA, Aprille JR (2003) Differential effects of typical and atypical neuroleptics on mitochondrial function in vitro. Arch Pharm Res 26:951-959

Myers RB, Fredenburg JL, Grizzle WI (2008) Carbohydrates. In: Bancroft JD, Gamble M (eds) Theory and practice of histological techniques, 6th edn. Churchill Livingstone, New York, pp 168-172

Nakamura BN, Fielder TJ, Hoang YD, Lim J, McConnachie LA, Kavanagh TJ, Luderer U (2011) Lack of maternal glutamate cysteine ligase modifier subunit $(\mathrm{Gclm})$ decreases oocyte glutathione concentrations and disrupts preimplantation development in mice. Endocrinol 152:2806-2815

Niehaus WG, Samuelsson B (1968) Formation of malonaldehyde from phospholipid arachidonate during microsomal lipid peroxidation. FEBS J 6:126-130

Parikha V, Khan MM, Mahadik SP (2003) Differential effects of antipsychotics on expression of antioxidant enzymes and membrane lipid peroxidation in rat brain. J Psychiatry Res 37:43-51

Patil S, Patil S, Bhaktaraj B, Patil SB (1999) Effect of graded doses of nicotine on ovarian and uterine activities in albino rats. Indian J Exp Biol 37:184-186

Pedersen T, Peters H (1968) Proposal for a classification of oocytes and follicles in the mouse ovary. J Reprod Fertil 17:555-557

Pillai A, Parikh V, Terry AV Jr, Mahadik SP (2007) Long-term antipsychotic treatments and crossover studies in rats: differential effects of typical and atypical agents on the expression of antioxidant enzymes and membrane lipid peroxidation in rat brain. J Psychiatr Res 41: 372-386

Polydoro M, Schröder N, Lima MN, Caldana F, Laranja DC, Bromberg E, Roesler R, Quevedo J, Moreira JC, Dal-Pizzol F (2004) Haloperidol-and clozapine-induced oxidative stress in the rat brain. Pharmacol Biochem Behav 78:751-756

Reinke A, Martins MR, Lima MS, Moreira JC, Dal-Pizzol F, Quevedo J (2004) Haloperidol and clozapine, but not olanzapine, induces oxidative stress in rat brain. Neurosci Lett 372:157-160 
Royce JS, Joe A, Jehoon L, Michael A, Sakhila B (2007) Chromium toxicity induces ovarian follicular developmental arrest, apoptosis, and deregulated steroidogenesis: Vitamin $\mathrm{C}$ restores follicular survival and function. Biol Reprod 77:215

Rung JP, Rung E, Johansson AM, Svensson K, Carlsson A, Carlsson ML (2011) Effects of the dopamine stabilizers (S)-(-)- OSU6162 and ACR16 on prolactin secretion in drug-naïve and monoaminedepleted rats. Naunyn Schmiedeberg's Arch Pharmacol 384:39-45

Saber AS, Hoda AM, Asmaa MA (2011) Suppressive effect of Ginkgo biloba extract (EGb761) on topsin induced ovarian toxicity and oxidative stress in albino rats. J Appl Pharm Sci 1:46-54

Sabha M Jr, Emirandetti A, Cullheim S, ALR O (2008) MHC1 expression and synaptic plasticity in different mice strains after axotomy. Synapse 62:137-148

Schleimer SB, Johnston GA, Henderson JM (2005) Novel oral drug administration in an animal model of neuroleptic therapy. J Neurosci Methods 146:159-164

Sinha AK (1972) Colorimetric assay of catalase. Anal Biochem 47:389394

Smith S, Wheeler MJ, Murray R, O'Keane V (2002) The effects of antipsychotic-induced hyperprolactinaemia on the hypothalamicpituitary-gonadal axis. J Clin Psychopharmacol 22:109-114

Spinazzi M, Casarin A, Pertegato V, Salviati L, Angelini C (2012) Assessment of mitochondrial respiratory chain enzymatic activities on tissues and cultured cells. Nat Protoc 7:1235
Subramanyam B, Woolf T, Castagnoli N (1991) Studies on the in vitro conversion of haloperidol to a potentially neurotoxic pyridinium metabolite. Chem Res Toxicol 4:123-128

Suzuki H, Kawaguchi T, Hasegawa T, Yonechi A, Ohsugi J, Higuchi M, Yamada F, Shio Y, Fujiu K, Kanno R, Ohishi A, Gotoh M (2006) Prognostic impact of $\mathrm{p} 53$ protein overexpression in patients with node-negative lung adenocarcinoma. Cancer Lett 237:242-247

Tesone M, Ladenheim RG, Chiauzzi VA, Charreau EH (1984) Effect of prolactin on the steroidogenic response of rat luteal cells. Mol Cell Endocrinol 36:187-194

Tilly JL, Tilly KI (1995) Inhibitors of oxidative stress mimic the ability of follicle-stimulating hormone to suppress apoptosis in cultured rat ovarian follicles. Endocrinology 136:242-252

Velasquez EV, Trigo RV, Creus S, Campo S, Croxatto HB (2006) Pituitary-ovarian axis during lactational amenorrhoea. I. Longitudinal assessment of follicular growth, gonadotrophins, sex steroids and inhibin levels before and after recovery of menstrual cyclicity. Hum Reprod 21:909-915

Publisher's note Springer Nature remains neutral with regard to jurisdictional claims in published maps and institutional affiliations. 